Rev. Bras. Saúde Prod. Anim., Salvador, v.14, n.1, p.224-232 jan./mar., 2013 http://www.rbspa.ufba.br ISSN 15199940

\title{
Desempenho bioeconômico de cabritos de diferentes grupos genéticos terminados em confinamento
}

\author{
Bioeconomic performance from goat kids differents genetics groups finished in \\ feedlot
}
CARTAXO, Felipe Queiroga ${ }^{1 *}$; LEITE, Mauricio Luiz de Mello Vieira ${ }^{2}$; SOUSA, Wandrick Hauss ${ }^{3}$; VIANA, Jefferson Alves ${ }^{3}$; ROCHA, Luciana Porangaba ${ }^{4}$

\footnotetext{
${ }^{1}$ Universidade Estadual da Paraíba, Departamento de Ciências Humanas e Agrárias, Catolé do Rocha, Paraíba, Brasil.

${ }^{2}$ Universidade Federal Rural de Pernambuco, Unidade Acadêmica de Serra Talhada, Serra Talhada, Pernambuco, Brasil.

${ }^{3}$ Empresa Estadual de Pesquisa Agropecuária da Paraíba, João Pessoa, Paraíba, Brasil.

${ }^{4}$ Universidade Federal da Paraíba, Programa de Doutorado Integrado em Zootecnia, Areia, Paraíba, Brasil.

*Endereço para correspondência: felipeqcartaxo@yahoo.com.br
}

\section{RESUMO}

Objetivou-se avaliar o desempenho e margem bruta de lucro de cabritos de diferentes grupos genéticos terminados em confinamento. Foram utilizados 30 cabritos não castrados, sendo 10 1/2 Anglo Nubiana $\times 1 / 2$ Sem Raça Definida, 10 1/2 Boer $\times 1 / 2$ Sem Raça Definida e 10 Sem Raça Definida, alimentados com dieta contendo $15,5 \%$ de proteína bruta e $2,58 \mathrm{Mcal}$ de energia metabolizável por quilograma de matéria seca. Os cabritos Boer $\times$ Sem Raça Definida (SRD) apresentaram maiores consumos de matéria seca, em percentual do peso vivo, em relação aos SRD, tendo obtido os Anglo Nubiana $\times$ SRD resultados semelhantes aos demais grupos genéticos. Os consumos de água, a conversão alimentar e o escore corporal ao final do confinamento não foram influenciados pelo grupo genético. No entanto, houve efeito significativo do grupo genético sobre o ganho de peso total e ganho de peso médio diário, que foram maiores para os cabritos Boer $\times$ SRD em comparação aos SRD. Os cabritos Anglo Nubiana $\times$ SRD e SRD obtiveram maiores escores corporais no início do experimento quando comparados com os Boer $x$ SRD. A utilização da raça Boer no cruzamento melhora o desempenho dos cabritos SRD. Os cabritos Boer $\times$ SRD, terminados em confinamento, apresentam maior margem bruta de lucro em comparação aos Anglo Nubiana $\times$ SRD.

Palavras-chave: análise econômica, Anglo Nubiana, Boer, caprinos, ganho de peso.

\section{SUMMARY}

The objective of this study was to evaluate performance and gross profit margin of goat kids finished in feedlot. Thirty kids noncastrated were used, being $101 / 2$ Anglo Nubian $\times 1 / 2$ undefined breed, $101 / 2$ Boer $\times 1 / 2$ undefined breed and 10 undefined breed, fed with diet containing $15.5 \%$ of crude protein and $2.58 \mathrm{Mcal} / \mathrm{kg}$ dry matter. The Boer $\times$ undefined breed kids showed greater dry matter intake, live weight percentual, in relation to undefined breed kids, obtained the Anglo Nubian $\times$ undefined breed kids similar results to the others genetics groups. The water intake, the feed conversion and the corporal score no influenced by genetics groups. However, there was significant effect of the genetics groups on the total weight gain and daily weight gain that were greater for the Boer $\times$ undefined breed kids when compared with undefined breed. The Anglo Nubian $\times$ undefined breed kids and undefined breed obtained greater corporal score at the beginning of the experiment when compared with Boer $\times$ undefined breed. The use of the Boer breed in the crossbred improves the performance of undefined breed kids. The Boer $\times$ undefined breed kids showed greater gross profit margin than the Anglo $\times$ undefined breed kids finished in feedlot.

Keywords: Anglo Nubian, Boer, economic analysis, goats, weight gain. 


\section{INTRODUÇÃOO}

A caprinocultura no Nordeste brasileiro sempre foi uma atividade de grande relevância econômica e social, contribuindo para a geração de alimentos, aumento da renda e inserção social. Destaca-se pela grande variabilidade de grupamentos genéticos e uma população de caprinos que corresponde a 90,6\% do efetivo nacional (IBGE, 2009). Apesar disso, esta atividade se caracteriza pela reduzida rentabilidade, devido, principalmente, à predominância do tipo de exploração extensiva na maioria dos criatórios.

A criação de caprinos em pastagens nativas é uma prática comum no Nordeste brasileiro, no entanto, estes pastos não fornecem todos os nutrientes necessários para o bom desempenho dos animais, principalmente caprinos puros ou mestiços Boer, que apresentam maiores exigências de produção.

Segundo Hashimoto et al. (2007) a terminação de cabritos em confinamento é uma alternativa a ser considerada, pois permite reduzir a idade de abate do animal e produzir maior quantidade de carne com qualidade.

Garcia et al. (2006) afirmaram que as raças Anglo Nubiana e Boer podem ser utilizadas na melhoria da qualidade da carne de caprinos Sem Raça Definida (SRD). Por sua vez, Menezes et al. (2007) afirmaram que a participação da raça Boer em cruzamentos melhorou o escore corporal, proporcionando vantagens econômicas ao produtor. Para Pereira Filho et al. (2008) a raça Boer pode constituir-se em uma boa alternativa para cruzamentos com outras raças e/ou tipos raciais criados no Brasil. No entanto, Sousa et al. (2009) afirmaram que os cabritos mestiços Anglo Nubiana apresentam menor compacidade do corpo em comparação aos mestiços
Boer, denotando menor aptidão para a produção de carne.

Segundo Pereira Filho et al. (2005) e Hashimoto et al. (2007) foram realizados poucos trabalhos no Brasil com animais cruzados Boer, no entanto, esses animais têm demonstrado desempenho de 80 a $210 \mathrm{~g} \mathrm{dia}^{-1}$.

$\mathrm{O}$ genótipo SRD é o de maior concentração no Nordeste do Brasil, oriundo da miscigenação de varias raças, caracteriza-se por não apresentar um padrão racial definido. Este genótipo sempre foi utilizado para produzir carne ou usado em cruzamentos, como raça materna, com reprodutores com aptidão para corte. Entretanto, pouco se conhece das características produtivas e econômicas do genótipo SRD e de seus cruzamentos.

Diante do exposto, objetivou-se avaliar o desempenho bioeconômico de cabritos de diferentes grupos genéticos terminados em confinamento.

\section{MATERIAL E MÉTODOS}

O experimento foi conduzido na Estação Experimental Pendência, pertencente à Empresa Estadual de Pesquisa Agropecuária da Paraíba (EMEPA-PB), localizada no município de Soledade, Semiárido paraibano, situada na Latitude $7^{\circ} 8^{\prime} 18^{\prime \prime} \mathrm{S}$ e Longitude $36^{\circ} 27^{\prime}$ 2", W, com altitude de $534 \mathrm{~m}$ e temperatura do ar média de $30^{\circ} \mathrm{C}$ e umidade relativa do ar média de $70,13 \%$.

Foram utilizados 30 caprinos não castrados, de três grupos genéticos, sendo 10 1/2 Anglo Nubiana $\times 1 / 2$ Sem Raça Definida (SRD), $101 \frac{1}{2}$ Boer $\times 1 / 2$ SRD e 10 SRD, com idade média de 150 dias e peso vivo médio de $19,05 \mathrm{~kg}$ no início do confinamento. Os animais foram criados até o inicio do ensaio em 
pastagem nativa (Caatinga), tendo acesso à suplementação mineral.

Os animais foram inicialmente vacinados contra clostridiose, desverminados por via oral com vermífugo à base de ivermectina a $1 \%$, devidamente identificados com brincos plásticos afixados nas orelhas, sendo em seguida distribuídos, após sorteio, em baias individuais cobertas, com piso ripado e suspenso, medindo $0,80 \times 1,20 \mathrm{~m}$, equipadas com comedouros e bebedouros individuais.

O período experimental foi precedido de 14 dias para adaptação dos animais às instalações, alimentação e manejo. Ao início do experimento e a cada 14 dias, os animais foram pesados, sempre às $7 \mathrm{~h}$ da manhã, após jejum alimentar por 16 horas. Estabeleceu-se o período de confinamento de 56 dias para o abate dos cabritos.

Durante o confinamento foi utilizada dieta única e completa, com 15,5\% de proteína bruta e 2,58 Mcal de energia metabolizável por quilograma de matéria seca, cuja composição alimentar e química estão apresentadas na Tabela 1 .

A ração utilizada, elaborada de acordo com o NATIONAL RESEARCH COUNCIL (NRC, 2007), foi fornecida duas vezes ao dia, às $7 \mathrm{~h}$ e às $15 \mathrm{~h}$. Estabeleceu-se um consumo de $5 \%$ do peso vivo de matéria seca, sendo reajustado e pesado diariamente em função das sobras de $10 \%$ para posteriores cálculos dos consumos de matéria seca (CMS). Quando os animais atingiram o período de confinamento pré-estabelecido, foram abatidos, sendo antes pesados, para cálculo do ganho de peso total (GPT), ganho de peso médio diário (GPMD) e conversão alimentar (CA).

$\mathrm{O}$ consumo de água (CAG) foi determinado quantificando-se a oferta e sobra durante 48 horas, semanalmente, por o todo período experimental. Tal observação iniciava-se às $7 \mathrm{~h}$, momento que a água era ofertada em recipientes plásticos com capacidade para 10 litros, preenchidos com sete e meio litros. Após completar 24 horas, às $7 \mathrm{~h}$ do dia seguinte, a sobra era pesada para estimar o consumo diário, repetindo-se este procedimento por mais um período de 24 horas.

Tabela 1. Composição alimentar e química da dieta experimental com base na matéria seca

\begin{tabular}{lr}
\hline \multicolumn{2}{c}{ Composição alimentar } \\
\hline Feno de maniçoba (\%) & 35,00 \\
Milho moído (\%) & 37,00 \\
Farelo de soja (\%) & 19,00 \\
Farelo de trigo (\%) & 5,50 \\
Óleo de soja (\%) & 2,00 \\
Sal mineral (\%)* & 0,50 \\
Calcáreo calcítico (\%) & 1,00 \\
\hline \multicolumn{2}{c}{ Composição química } \\
\hline Matéria seca (\%) & 88,80 \\
Proteína bruta (\%) & 15,53 \\
Energia metabolizável (Mcal/kg de MS) & 2,58 \\
Fibra em detergente neutro (\%) & 36,13 \\
Extrato etéreo (\%) & 4,73 \\
Carboidratos não fibrosos (\%) & 40,02 \\
Matéria mineral (\%) & 5,11 \\
\hline *Composição do suplemento mineral por \\
quilograma: Na 147g; Ca 120g; P 87g; S 18g; \\
Zn 3.800mg; Fe 3500mg; Mn 1.300mg; Fl \\
870mg; Cu 590mg; Mo 300mg; I 80 mg; Co \\
40mg; Cr 20mg; Se 15mg; Vit. A (UI) $250 \mathrm{mg;}$ \\
Vit. D (UI) 100mg; Vit. E (UI) 500mg.
\end{tabular}

A avaliação do escore corporal foi realizada no último dia do confinamento, por dois examinadores segundo a metodologia descrita por Cezar \& Sousa (2006). Para a atribuição dos escores foram feitas avaliações antes do abate, por meio de exame visual e tátil, pela palpação da região lombar e na inserção da cauda dos cabritos, com pontuação de 1 a 5 , com intervalos de 0,5, ponto, sendo: escore 1 - animais muito magros; escore 2 - 
magros; escore 3 - moderados; escore 4 - gordos; escore 5 - muito gordos ou obesos.

Como indicador econômico foi calculado a margem bruta de lucro (MB), mensurando o ganho de peso total durante o confinamento, o consumo médio de matéria seca, o período de confinamento, o custo de cada dieta e as despesas com vacinas e medicamentos. Esses cálculos foram de acordo com os determinados por Cartaxo et al. (2008) e a margem bruta de lucro foi obtida pela seguinte equação:

\section{$\mathrm{MB}=($ GPT $\mathrm{x} 4,50)-[(\mathrm{PC} \times \mathrm{CMMS} \mathrm{x}$} CD) + DVM]

Em que: $\mathrm{MB}=$ margem bruta de lucro (R\$/animal); GPT = ganho de peso durante o confinamento; $4,50=$ preço por $\mathrm{kg}$ vivo do animal praticado na região $(\mathrm{R} \$) ; \quad \mathrm{PC}=$ período $\mathrm{de}$ confinamento; $\mathrm{CMMS}=$ consumo médio de matéria seca; $\mathrm{CD}=$ custo da dieta; $\mathrm{DVM}=$ despesas com vacinas $\mathrm{e}$ medicamentos.

$\mathrm{O}$ delineamento utilizado foi $\mathrm{o}$ inteiramente casualizado com 10 repetições por genótipo. Utilizou-se o teste $\mathrm{F}$ para comparação dos quadrados médios do fator testado.

$\mathrm{O}$ modelo estatístico adotado foi Yijk = $\mu+\mathrm{Gi}+$ cijk, em que:

Yijk = valor observado da variável dependente estudada; $\mu=$ média geral; $\mathrm{Gi}=$ efeito do genótipo i; e rijk = erro aleatório associado a cada observação. As médias foram comparadas pelo teste de Tukey a $5 \%$ de probabilidade.

\section{RESULTADOS E DISCUSSÃO}

O consumo de matéria seca (CMS) da dieta, em percentual do peso vivo, diferiu significativamente $\quad(\mathrm{P}<0,05)$ entre os grupos genéticos (Tabela 2). Os cabritos Boer $\mathrm{x}$ SRD apresentaram maiores CMS, expressos em percentagem do peso vivo em relação aos SRD, enquanto os Anglo Nubiana $\times$ SRD foram semelhantes aos demais grupos genéticos avaliados. Isto denota que o cruzamento do genótipo local, o SRD, com raça especializada para corte, como a Boer, aumenta a ingestão de matéria seca dos cabritos quando terminados em confinamento, que pode repercutir em melhor desempenho, pois é a partir da ingestão de matéria seca que o animal estará consumindo maior ou menor quantidade de nutrientes (BROCHIER \& CARVALHO, 2008). Esta maior ingestão, provavelmente, ocorreu pela diferença existente entre as demandas nutricionais dos grupos genéticos Boer $x$ SRD e SRD.

A quantidade diária de matéria seca consumida pelos cabritos Boer $\times$ SRD $(952,60 \mathrm{~g})$, neste experimento, encontrase próxima a observada por Hashimoto et al. (2007), de 966g, e Carvalho Junior et al. (2011), de 953,36g, para animais de cruzamentos Boer.

Os consumos de água não foram influenciados pelo genótipo. Sabe-se que há uma alta e significativa correlação entre o consumo de matéria seca e a ingestão de água, fato não verificado nesta pesquisa. Segundo o NRC (1985) o consumo voluntário de água é duas a três vezes o consumo de matéria seca. Desse modo, os resultados do presente estudo estão coerentes com o referido boletim.

Os grupos genéticos apresentaram diferenças significativas $(\mathrm{P}<0,05)$ quanto ao ganho de peso total (GPT) e ganho de peso médio diário (GPMD), sendo maiores para os cabritos Boer $\times$ SRD $(10,26 \mathrm{~kg}$ de GPT e $183,21 \mathrm{~g} / \mathrm{dia}$ de GPMD) em comparação aos SRD $(7,74 \mathrm{~kg}$ de GPT e 138,21g/dia de GPMD). Os cabritos Anglo Nubiana $\times$ 
Rev. Bras. Saúde Prod. Anim., Salvador, v.14, n.1, p.224-232 jan./mar., 2013 http://www.rbspa.ufba.br ISSN 15199940

SRD apresentaram ganhos de peso $(8,47 \mathrm{~kg}$ de GPT e $151,25 \mathrm{~g} / \mathrm{dia}$ de GPMD) similares aos dois grupos genéticos. Isto indica que a inclusão da raça Boer no cruzamento com 0 genótipo SRD, promoveu melhoria no ganho de peso dos cabritos, devido ao maior potencial de crescimento da raça Boer em relação ao SRD, corroborando com Prieto et al. (2000) que afirmaram que o melhoramento dos caprinos Boer na África do Sul foi focalizado na seleção de atributos como tamanho, musculosidade e desempenho. Isto demonstra que a composição deste genótipo com nossas raças nativas pode incrementar a produção de carne desta espécie, entretanto os cabritos Boer $\times$ SRD não diferiram dos Anglo Nubiana $\times$ SRD, sugerindo que ambos os grupos genéticos (Boer e Anglo Nubiana) podem ser utilizados como raça paterna em sistemas de terminação em confinamento, dos quais se espera ganho de peso total e diário altos, reduzindo dessa forma, a permanência dos animais no sistema de criação citado.

Tabela 2. Desempenho dos caprinos, em função do genótipo

\begin{tabular}{|c|c|c|c|c|c|}
\hline \multirow{2}{*}{ Variável } & \multicolumn{3}{|c|}{ Genótipo } & \multirow{2}{*}{$\mathrm{CV}(\%)$} & \multirow{2}{*}{$\mathrm{P}$} \\
\hline & $\mathrm{AN} \times \mathrm{SRD}$ & $\mathrm{BO} \times \mathrm{SRD}$ & SRD & & \\
\hline Peso vivo inicial $(\mathrm{kg})$ & 20,19 & 18,20 & 18,78 & 10,28 & 0,083 \\
\hline Peso vivo final (kg) & 28,66 & 28,46 & 26,52 & 12,26 & 0,318 \\
\hline CMS (g/dia) & 921,70 & 952,60 & 815,30 & 18,57 & 0,173 \\
\hline CMS (\% PV) & $3,55^{\mathrm{ab}}$ & $3,85^{\mathrm{a}}$ & $3,40^{\mathrm{b}}$ & 10,47 & 0,038 \\
\hline CMS $\left(\mathrm{g} \mathrm{kg}^{0,75}\right)$ & 80,05 & 85,78 & 75,32 & 11,81 & 0,064 \\
\hline CAG (kg/dia) & 2,08 & 2,31 & 1,92 & 25,49 & 0,280 \\
\hline CAG $\left(\mathrm{g} \mathrm{kg}^{0,75}\right)$ & 181,29 & 207,49 & 177,74 & 19,84 & 0,172 \\
\hline CAG (\% PV) & 8,04 & 9,31 & 8,03 & 18,83 & 0,139 \\
\hline CAG $(\mathrm{kg} / \mathrm{kg} \mathrm{MS})$ & 2,28 & 2,40 & 2,37 & 18,13 & 0,805 \\
\hline GPT $(\mathrm{kg})$ & $8,47^{\mathrm{ab}}$ & $10,26^{\mathrm{a}}$ & $7,74^{\mathrm{b}}$ & 24,92 & 0,045 \\
\hline GPMD (g/dia) & $151,25^{\mathrm{ab}}$ & $183,21^{\mathrm{a}}$ & $138,21^{\mathrm{b}}$ & 24,92 & 0,045 \\
\hline $\mathrm{CA}(\mathrm{g} / \mathrm{g})$ & 6,30 & 5,41 & 6,16 & 23,78 & 0,332 \\
\hline ECI (1-5) & $1,85^{\mathrm{a}}$ & $1,45^{\mathrm{b}}$ & $1,80^{\mathrm{a}}$ & 17,35 & 0,010 \\
\hline ECF $(1-5)$ & 2,50 & 2,50 & 2,45 & 12,79 & 0,921 \\
\hline
\end{tabular}

SRD (Sem Raça Definida); AN $\times$ SRD (Anglo Nubiana $\times$ SRD); BO $\times$ SRD $($ Boer $\times$ SRD).

$\mathrm{CMS}=$ consumos de matéria; $\mathrm{CAG}=$ consumos de água, $\mathrm{GPT}=$ ganho de peso total, $\mathrm{GPMD}=$ ganho de peso médio diário, $\mathrm{CA}=$ conversão alimentar, $\mathrm{ECI}=$ escore corporal inicial; $\mathrm{ECF}=$ escore corporal final. $\mathrm{CV}=$ coeficiente de variação; $\mathrm{P}=$ probabilidade.

${ }^{\mathrm{a}, \mathrm{b}}$ Médias seguidas por letras distintas diferem $(\mathrm{P}<0,05)$ entre si pelo teste Tukey.

Dhanda et al. (2003) verificaram diferenças significativas entre cinco genótipos (Boer x Angorá, Boer x Feral , Boer x Saanen, Feral x Feral, Saanen $x$ Angorá e Saanen x Feral) para o ganho de peso médio diário. Da mesma forma, Urge et al. (2004), avaliando quatro distintos genótipos caprinos
(Alpina, Angorá, Boer e Spanish) terminados em confinamento, reportaram superioridade dos caprinos Boer em relação aos demais genótipos. Barreto et al. (2012) trabalhando com cabritos Moxotó e Canindé, com idade de 120 dias e peso médio de $15,3 \mathrm{~kg}$, também 
Rev. Bras. Saúde Prod. Anim., Salvador, v.14, n.1, p.224-232 jan./mar., 2013 http://www.rbspa.ufba.br ISSN 15199940

relataram diferenças entre os referidos genótipos.

Ressalta-se que os caprinos SRD são, geralmente, mantidos em sistema de criação extensivo, no ambiente semiárido do Nordeste brasileiro, em pastagens nativas (Caatinga), e, principalmente, com reduzida disponibilidade em quantidade e qualidade de forragem, notadamente nos períodos de estiagem (LEITE et al., 2009). Neste cenário, os caprinos SRD apresentam baixos índices produtivos.

Carvalho Junior et al. (2011) constataram que a suplementação melhora o desempenho de cabritos Boer $\times$ SRD terminados em pasto nativo. Peso final, ganho de peso total e ganho de peso médio diário foram influenciados $(\mathrm{P}<0,05)$ positiva e linearmente pelos níveis de suplementação. No maior nível de suplementação ( $1,5 \%$ do PV), o ganho de peso médio diário foi de $151 \mathrm{~g} / \mathrm{dia}$, sendo inferior ao obtido no presente estudo de 183,21 g/dia.

A conversão alimentar não diferiu $(\mathrm{P}>0,05)$ entre os grupos genéticos avaliados. Isto indica que os animais apresentaram semelhança na transformação da matéria seca contida na dieta em peso corporal. Por outro lado, a explicação para a conversão alimentar não ter sido diferente se deve ao fato do consumo de matéria seca expresso em $\mathrm{kg} /$ dia também não ter apresentado diferença significativa. Sabe-se que a conversão alimentar é a relação entre o consumo de matéria seca e o ganho de peso médio diário.

Vale salientar que a conversão alimentar verificada no presente estudo pode ser considerada aceitável, levandose em consideração a espécie caprina. Valores superiores foram reportados por Hashimoto et al. (2007) que avaliaram o desempenho de cabritos Boer x Saanen alimentados com rações contendo casca do grão de soja em substituição ao milho, e verificaram conversão alimentar média para os machos de $12,05 \mathrm{~g} / \mathrm{g}$.

Os cabritos Anglo Nubiana $\times$ SRD e SRD obtiveram maiores escores corporais no início do experimento quando comparados com os Boer $x$ $\mathrm{SRD}$, no entanto, não houve efeito do genótipo sobre o escore corporal ao final do confinamento. Isto sugere que os cabritos Boer $\times$ SRD apresentaram maior velocidade de crescimento e depositaram maior quantidade de tecido muscular e adiposo em relação aos demais grupos genéticos durante $o$ confinamento, evidenciado pelo aumento de mais de um ponto entre o escore corporal inicial e final, que, proporcionou semelhança entre os escores corporais finais. $O$ grau de acabamento do animal, relacionado com a carcaça que será obtida após o abate está diretamente relacionado ao escore corporal do animal vivo, por isso, o genótipo determina diferentes velocidades no desenvolvimento dos grupos de tecidos (MENDONÇA et al., 2003).

Os cabritos Boer $x$ SRD e SRD apresentaram margem bruta de lucro positiva, no entanto, para os Anglo Nubiana $x$ SRD este resultado econômico foi negativo (Tabela 3). O valor de margem bruta de lucro de $\mathrm{R} \$$ 6,27/animal alcançado pelos mestiços Boer foi muito superior ao $\mathrm{R} \$$ 0,54/animal obtido pelos SRD. Isto indica que a heterose oriunda do cruzamento da raça Boer com o genótipo local, o SRD, acarretou efeito positivo e que a terminação em confinamento de cabritos oriundos desse cruzamento proporcionou maior retorno econômico em comparação ao genótipo SRD e ao cruzamento do genótipo SRD com a raça Anglo Nubiana, que apresentou resultado negativo. Estes resultados podem ser atribuídos, principalmente, 
Rev. Bras. Saúde Prod. Anim., Salvador, v.14, n.1, p.224-232 jan./mar., 2013 http://www.rbspa.ufba.br ISSN 15199940

pelo maior ganho de peso total dos Boer $x$ SRD durante a terminação em confinamento.

Vale salientar que apesar do baixo valor verificado para os SRD e negativo para os Anglo Nubiana x SRD. A terminação em confinamento de cabritos se justifica por reduzir a idade de abate, repercutindo em melhoria na qualidade da carne; por agregar valor ao preço por $\mathrm{kg}$ vivo do animal pela oferta de carne no período de entressafra; por diminuir o índice de mortalidade, pois os animais ficam em área restrita e não estão expostos a predadores ou e doenças carências durante o período de escassez de forragens; por minimizar o impacto ambiental, decorrente da seletividade dos caprinos levando a extinção de algumas forrageiras arbustivas e arbóreas, como também redução da compactação do solo; por reduzir a infestação de verminose das pastagens, pela redução do efetivo presente na mesma e por aumento na taxa de desfrute do rebanho.

Tabela 3. Margem bruta de lucro dos caprinos, em função do genótipo

\begin{tabular}{lccc}
\hline \multirow{2}{*}{ Variável } & \multicolumn{3}{c}{ Genótipo } \\
\cline { 2 - 4 } & AN $\times$ SRD & BO $\times$ SRD & SRD \\
\hline Observações & 10 & 10 & 10 \\
Peso inicial $(\mathrm{kg})$ & 20,19 & 18,20 & 18,78 \\
Peso final $(\mathrm{kg})$ & 28,66 & 28,46 & 26,52 \\
Ganho de peso total $(\mathrm{kg})$ & 8,47 & 10,26 & 7,74 \\
Preço cabrito vivo (kg) & 4,50 & 4,50 & 4,50 \\
Custo da dieta (kg de MS (R\$)) & 0,73 & 0,73 & 0,73 \\
Consumo médio da dieta MS/cabrito (kg) & 0,921 & 0,952 & 0,815 \\
Período de confinamento (dias) & 56 & 56 & 56 \\
Despesas com vacina e medicamentos $(\mathrm{R} \$)$ & 0,96 & 0,96 & 0,96 \\
Margem bruta de lucro/cabrito $(\mathrm{R} \$)$ & $-0,52$ & 6,27 & 0,54 \\
\hline
\end{tabular}

SRD (Sem Raça Definida); AN $\times$ SRD (Anglo Nubiana $\times$ SRD); BO $\times$ SRD $($ Boer $\times$ SRD).

$\mathrm{CV}=$ coeficiente de variação; $\mathrm{P}=$ probabilidade.

Cartaxo et al. (2008) e Sousa et al. (2012) avaliando o desempenho bioeconômico de cordeiros terminados em confinamento, observaram menor margem bruta de lucro para os animais mestiços SRD quando comparados com os mestiços com raça especializada para corte. Da mesma forma do presente estudo os animais mestiços com raça especializada para corte obtiveram os maiores resultados.

A utilização da raça Boer no cruzamento melhora o desempenho dos cabritos SRD, aumentando o ganho de peso total e o ganho de peso médio diário. Os cabritos Boer $\times$ SRD, terminados em confinamento, apresentam maior margem bruta de lucro em comparação aos Anglo Nubiana $\times$ SRD e SRD.

\section{REFERÊNCIAS}

BARRETO, L.M.G.; MEDEIROS, A.N.; BATISTA, Â.M.V.; ARAÚJO, G.G.L.; FURTADO, D.A.; LISBOA, A.C.C.; PAULO, J.L.A.; ALVES, A.R. Growth performance of native goats fed diets containing different levels of 
Rev. Bras. Saúde Prod. Anim., Salvador, v.14, n.1, p.224-232 jan./mar., 2013 http://www.rbspa.ufba.br ISSN 15199940

energy. Revista Brasileira de

Zootecnia, v.41, n.3, p.675-682, 2012.

BROCHIER, M.A.; CARVALHO, S. Consumo, ganho de peso e análise econômica da terminação de cordeiros em confinamento com dietas contendo diferentes proporções de resíduo úmido de cervejaria. Arquivo Brasileiro de Medicina Veterinária e Zootecnia, v.60, n.5, p.1205-1212, 2008.

CARTAXO, F.Q.; SOUSA, W.H.; CEZAR, M.F.; GONZAGA NETO, S.; CUNHA, M.G.G. Efeitos do genótipo e da condição corporal sobre o desempenho de cordeiros terminados em confinamento. Revista Brasileira de Zootecnia, v.37, n.8, p.1483-1489, 2008.

CARVALHO JÚNIOR, A.M.; PEREIRA FILHO, J.M.; SILVA, R.M.; SILVA, A.M.AZEVÊDO; C.M.F. Effect of supplementation on the performance of F1 crossbred goats finished in native pasture. Revista Brasileira de Zootecnia, v.40, n.11, p.2510-2517, 2011.

CEZAR, M.F.; SOUSA, W.H. Avaliação e utilização da condição corporal como ferramenta de melhoria da reprodução e produção de ovinos e caprinos de corte. Revista Brasileira de Zootecnia, v.35, p.541-565, 2006. Supl. especial.

DHANDA, J.S.; TAYLOR, D.G.; MURRAY, P.J. Growth, carcass and meat quality parameters of male goats: effects of genotype and liveweight at slaughter. Small Ruminant Research, v.50, n.1/2, p.57-66, 2003.

GARCIA. M.H.O.; BEZERRA, F.J.; SANTOS FILHO, J.M.; RONDINA, D; SILVA, D.P.G.; OLIVEIRA FILHO, J.P. Aspectos qualitativos das carcaças de caprinos AngloNubiana x SRD e Boer x SRD abatidos em duas faixas de peso. Revista Científica Eletrônica de Medicina Veterinária, n.6, p.1-7, 2006.

HASHIMOTO, J.H.; ALCALDE, C.R.; ZAMBOM, M.A.; SILVA, K.T.; MACEDO, F.A.F.; MARTINS, E.N.; RAMOS, C.E.C.O.; PASSIANOTO, G.O. Desempenho e digestibilidade aparente em cabritos Boer $\times$ Saanen em confinamento recebendo rações com casca do grão de soja em substituição ao milho. Revista Brasileira de

Zootecnia, v.36, n.1, p.174-182, 2007.

INSTITUTO BRASILEIRO DE GEOGRAFIA E ESTATÍSTICA IBGE. Produção da pecuária municipal. Rio de Janeiro: IBGE, v.37, p.1-55, 2009. Disponível em: $<$ http://www.ibge.gov.br/home/estatistic a/economia/ppm/2009/ ppm2009.pdf.> Acesso em: 23 abr. 2012.

LEITE, M.L.M.V.; SANTOS, E.M.; SOUSA, W.H.; CARTAXO, F.Q.; CUNHA, M.G.G. Estratégias para alimentação de caprinos e ovinos no Semiárido brasileiro. In: SIMPOSIO INTERNACIONAL SOBRE CAPRINOS E OVINOS DE CORTE, 4., 2009, João Pessoa. Anais... João Pessoa: SINCORTE, 2009.

MENDONÇA, G.; OSÓRIO, J.C. OLIVEIRA, N.M.; OSÓRIO, M.T.; ESTEVES, R.; WIENGARD, M.M. Morfologia, características da carcaça e componentes do peso vivo em borregos Corriedale e Ideal. Ciência Rural, v.33, n.2, p.351-355, 2003.

MENEZES, J.J.L.; GONÇALVES, H.C.; RIBEIRO, M.S.; RODRIGUES, L.; CAÑIZARES, G.I.L.; MEDEIROS, B.B.L.; GIASSETTI, A.P. Desempenho e medidas biométricas de caprinos de 
Rev. Bras. Saúde Prod. Anim., Salvador, v.14, n.1, p.224-232 jan./mar., 2013 http://www.rbspa.ufba.br ISSN 15199940

diferentes grupos raciais. Revista

Brasileira de Zootecnia, v.36, n.3, p.635-642, 2007.

NATIONAL RESEARCH COUNCIL NRC. Nutrient requirements of sheep. 6.ed. Washington, D.C.: National Academy Press, 1985. 99p.

NATIONAL RESEARCH COUNCIL NRC. Nutrient Requirements of Small Ruminants: sheep, goats, cervids and New World camelids. Washington: National Academy Press, 2007. 362p.

PEREIRA FILHO, J.M.; RESENDE, K.T.; TEIXEIRA, I.A.M.A.; SILVA SOBRINHO, A.G.;YÁÑEZ, E.A.; FERREIRA, A.C.D. Efeito da restrição alimentar no desempenho produtivo e econômico de cabritos F1 Boer x Saanen. Revista Brasileira de Zootecnia, v.34, n.1, p.188-196, 2005.

PEREIRA FILHO, J.M.; RESENDE, K.T.; TEIXEIRA, I.A.M.A.; SILVA SOBRINHO, A.G.; YÁÑEZ, E.A.; FERREIRA, A.C.D. Características da carcaça e alometria dos tecidos de cabritos F1 Boer $\times$ Saanen. Revista Brasileira de Zootecnia, v.37, n.5, p.905-912, 2008.

PRIETO, I.; GOETSCH, A.L.; BANSKALIEVA, V.; CAMERON, M.; PUCHALA, R.; SAHLU, T.; DAWSON, L.J.; COLEMAN, S.W.

Effects of dietary protein concentration on postweaning growth of Boer crossbred and Spanish goat wethers. Journal Animal Science, v.78, p.22752281, 2000.
SOUSA, W.H.; BRITO, E.A.; MEDEIROS, A.N.; CARTAXO, F.Q.; CEZAR, M.F.; CUNHA, M.G.G. Características morfométricas e de carcaça de cabritos e cordeiros terminados em confinamento. Revista Brasileira de Zootecnia, v.38, n.7, p.1340-1346, 2009.

SOUSA, W.H.; CARTAXO, F.Q.; COSTA, R.G.; CEZAR, M.F.; CUNHA, M.G.G.; PEREIRA FILHO, J.M.P.; SANTOS, N.M. Biological and economic performance of feedlot lambs feeding on diets with different energy densities. Revista Brasileira de Zootecnia, v.41, n.5, p.1285-1291, 2012.

URGE, M.; MERKEL, R.C.; SAHLU, T.; ANIMUT, G.; GOETSCH, A.L. Growth performance by Alpine, Angora, Boer and Spanish wether goats consuming 50 or $75 \%$ concentrate diets. Small Ruminant Research, v.55, p.149-158, 2004.

Data de recebimento: 01/11/2012

Data de aprovação: 18/03/2013 